\title{
Removal of Cyanide from Wastewater Using Electrocoagulation
}

\author{
Abdelsalam Elawwad ${ }^{1}$, Ahmed Hamdy ${ }^{2}$ \\ ${ }^{1}$ Environmental Engineering Dept., Faculty of Engineering, Cairo University \\ El-Gamaa St., 12613 Giza, Egypt \\ ${ }^{2}$ Environmental Engineering Program, Zewail City of Science and Technology \\ $6^{\text {th }}$ October City, 12578, Giza, Egypt \\ elawwad@cu.edu.eg, ahsadek@zewailcity.edu.eg
}

\section{Extended Abstract}

Free cyanide and its related compounds are toxic to human and other living organisms [1]. High concentrations of cyanide can be found in various industrial wastewaters such as coke-oven wastewater [2]. Cyanide has a strong inhibitory effect on biodegradation which makes using conventional biological treatment difficult [2]. Electrocoagulation (EC) could be an alternative process that can be used for cyanide removal from wastewater that contains cyanide [1]. In this research, the ability of Electrocoagulation in removing Cyanide from wastewater was deeply investigated. A stock synthetic cyanide wastewater was prepared with different concentrations using $\mathrm{KCN}$ with initial $\mathrm{pH}$ was 10. EC experiments were carried out in a batch EC reactor consists of a beaker with $200 \mathrm{ml}$ volume and iron electrodes which were connected by a DC power supply $(0$ to $30 \mathrm{~V})$. The influence of key operating parameters, such as electrolysis time (t) (5-60 min), current density (CD) $\left(0.625,0.750,0.875,1.125,1.25\right.$ and $\left.1.875 \mathrm{~mA} / \mathrm{cm}^{2}\right)$, initial cyanide concentration $\left(\mathrm{C}_{0}\right)(50,75,100,150 \mathrm{and} 200 \mathrm{mg} / \mathrm{L})$, was taken into accounts. SEM morphology was used to investigate the influence of the EC process on the morphology of the surface of the iron anodes before and after the EC process. The weight of the electrodes was measured before and after the experiments and it was found that there is an excellent agreement between the theoretical and the experimental measurements of weight loss of iron electrode. The results showed that at a constant applied density of $0.625 \mathrm{~mA} / \mathrm{cm}^{2}$ and initial concentrations of $100 \mathrm{mg} / 1$, the removal rates increased progressively from 5 to $45 \mathrm{~min}$ from 1.2 to $24 \%$ respectively. The best current value for cyanide removal by EC process in the interval of current densities investigated in this work was found to be $1.875 \mathrm{~mA} / \mathrm{cm}^{2}$ with a removal efficiency of $99.2 \%$. At lower initial concentrations of cyanide, there is no significant difference in the removal percentage. However, it has been observed that on increasing the initial concentration of cyanide from 50 to $200 \mathrm{mg} / \mathrm{L}$, the removal efficiency decreased from $94.4 \%$ to $20 \%$. SEM images indicated that the virgin anode surface was uniform and homogenous except for small scratches, while after a series of EC experiments, the anode surface became inhomogeneous, with several dents. This could be attributed to the consumption of anode material at the active sites where the anode dissolution results in the generation of iron hydroxides (coagulation ions). Our future work will concentrate on the treatment of the sludge generated from the proposed treatment scheme where it represents a major portion of the operational costs and could have negative environmental and public health impacts [3]. Also, modifications of the electrodes by using nanoparticles could represent a vital solution to increase their surface area and system performance [4].

\section{References}

[1] Hassani, G., Nasseri, S., Gharibi, H., "Removal of Cyanide by Electrocoagulation Process", Analytical \& Bioanalytical Electrochemistry, 3, pp. 625-634, 2011.

[2] Elawwad, A., Naguib, A., Abdel-halim, H., "Modeling of phenol and cyanide removal in a full-scale coke-oven wastewater treatment plant”, Desalin. Water Treat., 57 (52), pp. 25181-25193, 2016.

[3] Elawwad, A., Hazem, M. "Minimization of sludge production in an integrated UASB-continuous flow sequencing batch reactor system," Desalination and Water Treatment, 91, pp. 206-213, 2017.

[4] Elawwad, Abdelsalam, Ragab, M., Hamdy, A., Husein, D., "Enhancing the performance of microbial desalination cells using $\delta \mathrm{MnO} 2$ /graphene nanocomposite as a cathode catalyst", Journal of Water Reuse and Desalination, 10 (3), 2020. 